\title{
Fatores que levam a alta incidência da síndrome de Burnout nos profissionais da enfermagem
}

\author{
Factors that lead to a high incidence of Burnout syndrome in nursing professionals \\ Factores que conducen a una alta incidencia de síndrome de Burnout en profesionales de \\ enfermería
}

Raimunda Liliane Beleza Vilaço ${ }^{1 *}$, Daiane Gonçalves ${ }^{1}$, Vanderson Ferreira da Silva ${ }^{1}$, Jabneela Vieira Pereira Vetorazo'.

\section{RESUMO}

Objetivo: Identificar os fatores que levam a alta incidência da síndrome de Burnout nos profissionais da enfermagem, bem como, entender mecanismos fisiológicos e a atenção à saúde no contexto do enfermeiro. Métodos: Desenvolveu-se revisão integrativa da literatura, qualitativa/qualitativa, efetivada entre os meses de Janeiro 2021 a Abril 2021, fazendo uso das bases de dados da Acervo+, Literatura Internacional em Ciências da Saúde (PUBMED), Literatura Latino-Americana e do Caribe em Ciências da Saúde (LILACS), na Biblioteca Eletrônica Científica Online (SciELO) e Biblioteca Virtual em Saúde (BVS), sendo incluídos publicações que estavam disponibilizadas na íntegra, livre acesso, nos idiomas português, inglês e espanhol, no período entre 2015 a 2020. Resultados: Encontraram-se 114 artigos nas bases de dados, e após a aplicação dos critérios de exclusão, selecionados 21 artigos para subsidiar a revisão de literatura. Considerações Finais: Os fatores desencadeadores do Burnout evidenciados nesse estudo foram, entre outros, sobrecarga laboral, baixa remuneração, condições inadequadas de trabalho, ausência de Equipamentos de Proteção Individual, ambiente de trabalho conflituoso.

Palavras-chave: Síndrome de Burnout, Incidência, Profissionais da enfermagem.

\begin{abstract}
Objective: To identify the factors that lead to a high incidence of Burnout syndrome in nursing professionals, as well as physiological mechanisms and health care in the context of nurses. Methods: An integrative qualitative/qualitative literature review was carried out between January 2021 and April 2021, using databases from Acervo+, International Literature in Health Sciences (PUBMED), Latino-American and Caribbean in Health Sciences (LILACS), in the Online Scientific Electronic Library (SciELO) and Virtual Health Library (VHL), including publications that were available in full, free access, in Portuguese, English and Spanish, in the period between 2015 and 2020. Results: 114 articles were found in the databases, and after applying the exclusion criteria, 21 articles were selected to support the literature review. Final Considerations: The triggering factors of burnout evidenced in this study were, among others, work overload, low pay, inadequate working conditions, OIE of Personal Protective Equipment, conflicting work environment.
\end{abstract}

Key words: Burnout syndrome, Incidence, Nursing professionals.

\section{RESUMEN}

Objetivo: Identificar los factores que conducen a una alta incidencia del síndrome de Burnout en los profesionales de enfermería, así como los mecanismos fisiológicos y asistenciales en el contexto de las enfermeras. Métodos: Se realizó una revisión integradora cualitativa / cualitativa de la literatura entre enero de 2021 y abril de 2021, utilizando bases de datos de Acervo+, Literatura Internacional en Ciencias de la Salud (PUBMED), Latinoamericana y Caribeña en Ciencias de la Salud (LILACS), en el Online. Biblioteca Electrónica Científica (Scielo) y Biblioteca Virtual en Salud (BVS), incluidas las publicaciones que estuvieron

${ }^{1}$ União das Escolas Superiores de Rondônia (UNIRON), Porto Velho - RO.

*E-mail: lilianebeleza91@gmail.com

SUBMETIDO EM: 5/2021

ACEITO EM: 6/2021

PUBLICADO EM: 7/2021 
disponibles en acceso completo, gratuito, en portugués, inglés y español, en el período comprendido entre 2015 y 2020. Resultados: Se encontraron 114 artículos en las bases de datos, y luego de aplicar los criterios de exclusión, se seleccionaron 21 artículos para apoyar la revisión de la literatura. Consideraciones finales: Los factores desencadenantes del burnout evidenciados en este estudio fueron, entre otros, sobrecarga de trabajo, salarios bajos, condiciones de trabajo inadecuadas, OIE de Equipos de Protección Personal, ambiente de trabajo conflictivo.

Palabras clave: Síndrome de Burnout, Incidencia, Profesionales de enfermería.

\section{INTRODUÇÃO}

Na última década os transtornos mentais nos trabalhadores de enfermagem têm alcançado maior expressividade, demonstrando uma séria problemática no âmbito da saúde do trabalhador e para os serviços de saúde, no contexto internacional, destacando entre elas, a síndrome de Burnout (BALDONEDO MM, et al., 2019).

A síndrome de Burnout já havia sido definida como doença (Classificação Internacional de Doenças (CID) 10), mas em 29 de maio de 2019, foi abrangida na mesma categoria da CID-11, sendo que desde então a definição é mais particularizada. A Organização Pan-Americana de Saúde (OPAS), definiu Burnout como uma síndrome resultante do estresse crônico no local de trabalho que não foi gerenciado com sucesso. Ou seja, a Burnout se refere designadamente a fenômenos no contexto ocupacional e não deve ser empregada para descrever experiências em outras áreas da vida (OPAS, 2019).

Pinto M (2015), afirmam que a Síndrome de Burnout é um acontecimento psicossocial que ocorre devido a fatores inadequados no ambiente de trabalho ocasionando estresse crônico, sobretudo a sobrecarga emocional causada por se lidar excessivamente com pessoas. Branco FMFC, et al., (2020) apontam que a dinâmica própria do trabalho da enfermagem pode gerar sobrecarga de movimento e tensão ocupacional, além de agravos como ansiedade, insônia, mudanças dos níveis pressóricos, sentimento de baixa autoestima, entre outros, que somados podem acarretar problemas no campo profissional e pessoal.

O homem precisa se adaptar continuamente as mudanças que ocorrem no seu modo de vida, e isso pode implicar em maior estresse emocional e tensão psicológica frente aos desafios. Quando essas mudanças acontecem no ambiente de trabalho, pode influenciar negativamente a sua saúde, e este vem a apresentar sintomas físicos e psicológicas que prejudicam o seu desempenho (FRANCA FM e FERRARI R, 2012).

A abordagem deste tema se faz importante mediante a incidência de profissionais da enfermagem que são acometidos com esta síndrome. A enfermagem abrange os enfermeiros, técnicos e auxiliares de enfermagem, os quais operam em equipe com a finalidade do cuidado ao ser humano, e baseiam-se na responsabilidade ética, legal e técnica, envolve atitudes de dedicação, zelo, espírito de sacrifício e de caridade (SANTOS EN, et al., 2019).

No Brasil, de acordo com o Conselho Federal de Enfermagem, a enfermagem brasileira é composta por $80 \%$ de técnicos e auxiliares e $20 \%$ de enfermeiros. Desse, $59,3 \%$ da enfermagem encontra-se no setor público no Brasil, 38\% no setor privado, 14, 6\% no setor filantrópico e $8,2 \%$ nas instituições de ensino. Uma pesquisa recente desenvolvida pela Confederação Nacional dos Trabalhadores da Saúde apontou que 87\% destes profissionais apresentam sintomas da síndrome do Burnout (BRASIL, 2020).

Atualmente no Brasil, grande parte dos profissionais da enfermagem tem uma jornada laboral muito estressante, são sobrecarregados de tarefas e exigências, o que somados a uma rotina voltada a acompanhar pacientes com dores, e em situação de morte, a qual leva o profissional a vivenciar sentimento de impotência e sofrimento mental decorrentes da empatia, qualidade importante para a enfermagem. São fatores determinantes para o desencadeamento de situação de estresse e síndrome de Burnout (OLIVEIRA RF, et al., 2017).

A incidência desta síndrome nos profissionais de enfermagem (cerca de $87 \%$ ) já é preocupação do Ministério da Saúde e do Conselho Federal de Enfermagem. Sendo que, o Ministério da Saúde se posiciona 
afirmando que os trabalhadores da saúde em estado de estresse, que trabalham mesmo com sintomas da síndrome de Burnout (tensão emocional, físico e mental), estão mais propensos a cometer erros graves, prejudicando a saúde dos usuários (BRASIL, 2019; BRASIL, 2020).

Salienta-se que, a Síndrome de Burnout se tornou uma questão de saúde pública a nível mundial, e de acordo com a Internacional Stress Management Association (ISMA), uma associação internacional de pesquisa e prevenção ao tratamento do estresse, o Japão aparece em primeiro lugar, com $70 \%$ da população economicamente ativa sofrendo de Burnout. Em segundo lugar, o Brasil, com 30\%, seguido pela China com $24 \%$, Estados Unidos com 20\% com o maior número de pessoas afetadas pela Síndrome de Burnout, caracterizada pelo alto nível de estresse, no mundo (ISMA, 2020).

Estudos afirmam a alta vulnerabilidade desses profissionais a essa síndrome e o aumento gradativo de profissionais da enfermagem acometidos pelo Burnout no Brasil, que relatam sofrimento e sentimento de impotência, medo, insegurança, ansiedade bem como, sentem-se desqualificados, desamparados (FERREIRA GB, et al., 2017).

A referida síndrome se insere no campo das doenças ocupacionais, levando o indivíduo a uma despersonalização e baixa realização profissional, em decorrência de aspectos em seu ambiente de trabalho sendo caracterizada como sensação de estar esgotado físico mental e emocional. É preocupante tal situação, tendo em vista que o sofrimento do indivíduo traz consequências sobre o seu estado de saúde e igualmente sobre o seu desempenho profissional, pois desencadeiam disfunções pessoais e organizacionais, fazendo com que os mesmos adoeçam (FERREIRA GB, et al., 2017).

Face ao exposto, o presente estudo teve como objetivo de identificar os fatores que levam a alta incidência da síndrome de Burnout nos profissionais da enfermagem. Os resultados podem oferecer informações importante para que se intervenha nesta situação, a fim de melhoras as condições de trabalho dos referidos.

\section{MÉTODOS}

Trata-se de uma revisão integrativa da literatura, utilizada por seu potencial de organização, síntese de conhecimentos e identificação de lacunas que contribuem na análise crítica de um objeto de estudo proposto. Para isso, seguiu-se os seis passos para seu desenvolvimento: formulação da questão norteadora; busca na literatura; extração dos dados dos estudos selecionados; avaliação dos estudos; interpretação e síntese dos resultados; apresentação da revisão integrativa.

Para responder ao objetivo do presente estudo, formulou-se a seguinte questão norteadora: "O que as produções científicas disponíveis na literatura nacional, abordam referente aos fatores que influenciam o desencadeamento da Síndrome do Burnout nos profissionais de enfermagem?"

O levantamento bibliográfico foi realizado nas bases de dados da Literatura Latino-Americana e do Caribe em Ciências da Saúde (LILACS), Acervo+, Literatura Internacional em Ciências da Saúde (PUBMED), na Biblioteca Eletrônica Científica Online (SciELO) e Biblioteca Virtual em Saúde (BVS), o que possibilitou a busca por estudos publicados no cenário nacional.

Para a seleção dos estudos, optou-se pela inclusão de artigos científicos disponíveis na íntegra, em livre acesso, publicados no período entre 2015 a 2020, nos idiomas português, bem como aqueles que, após leitura do título e resumo, abordassem aspectos relacionados à temática do estudo. Foram excluídos os artigos duplicados, artigos de revisão, de reflexão/debates, monografias, dissertações, teses, comentários, editoriais e cartas.

Os estudos elegíveis foram lidos na íntegra, a fim de incluir ou não, aqueles que conseguissem responder à questão norteadora. A interpretação e síntese dos resultados encontrados será apresentada em uma tabela contendo os autores, ano, local e periódico de publicação, bem como os principais resultados quanto aos fatores que influenciam o desencadeamento da Síndrome de Burnout nos profissionais de enfermagem. 


\section{RESULTADOS}

Foram encontrados 114 artigos nas bases de dados, dos quais em um primeiro momento, foram excluídos 8 estudos por estarem indisponíveis, por estarem inferiores ao período previamente selecionado, 19 por estarem duplicados, 8 por serem artigos de revisão. Após a leitura de título e resumo, 32 artigos foram selecionados para leitura na íntegra, e 11 foram excluídos por não corresponderem ao propósito da pesquisa, o que possibilitou ao final, a inclusão de 21 artigos para serem analisados a fim de subsidiar a revisão de literatura (Figura 1).

Figura 1 - Fluxograma das etapas para a seleção dos artigos desta revisão integrativa, 2021.

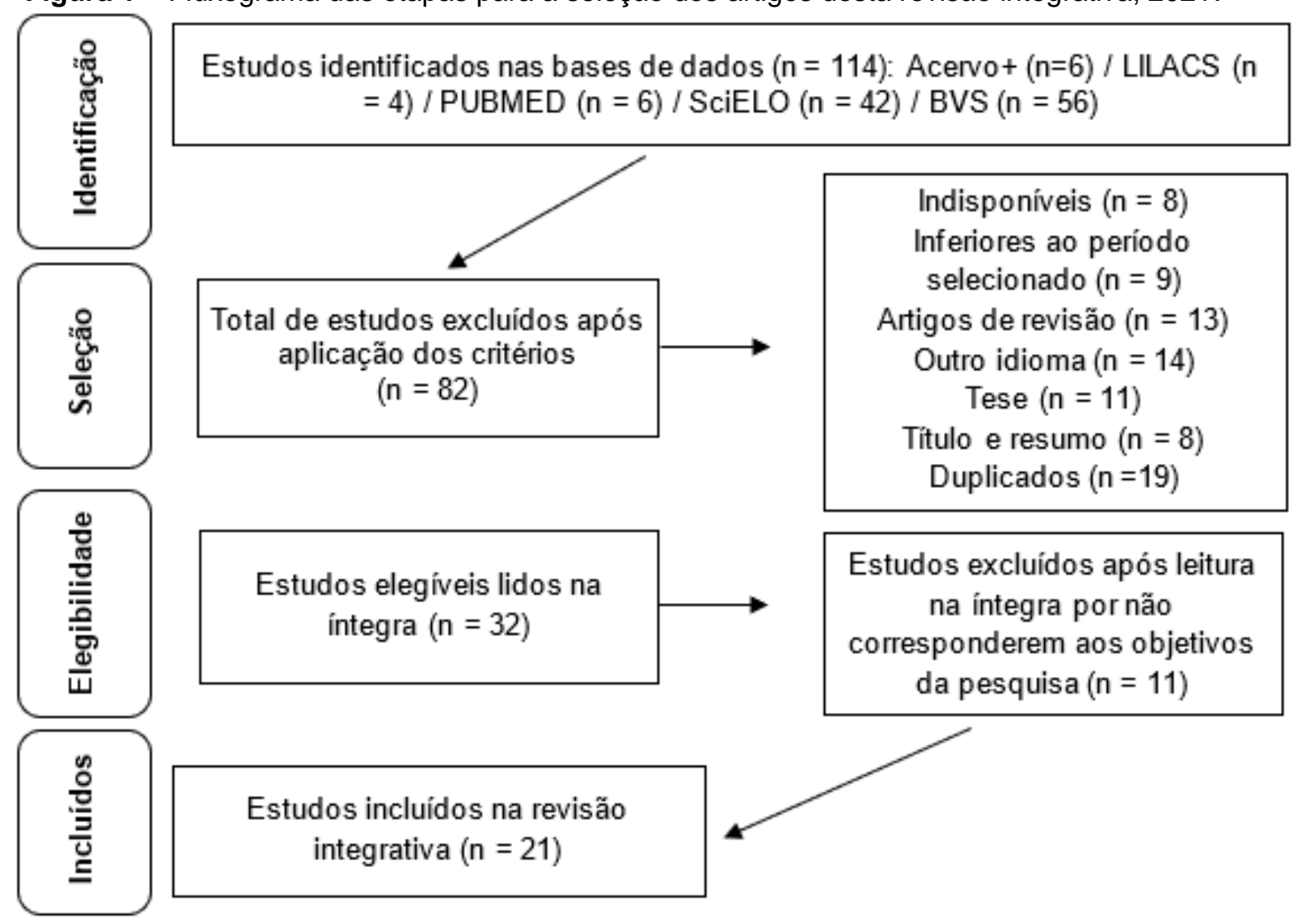

Fonte: Vilaço RLB, et al., 2021.

Dos artigos incluídos na revisão, a maioria foi publicado no idioma português (99\%), e apenas um no idioma inglês (1\%), que foi traduzido. Quanto ao tipo de estudo, identificou-se majoritariamente, pesquisas do tipo observacionais (28\%), Experimental (5\%), transversais analíticos (14\%), transversais com abordagens qualitativa (29\%) / quantitativa (24\%) (Quadro 1). 


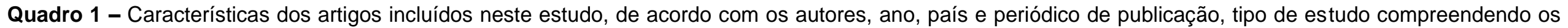
fatores que levam a alta incidência da síndrome de Burnout nos profissionais da enfermagem.

\begin{tabular}{|c|c|c|c|}
\hline Autores & Ano, cidade e periódico de publicação & Tipo de estudo & Vertente do artigo \\
\hline $\begin{array}{l}\text { BALDONEDO MM, et } \\
\quad \text { al. }\end{array}$ & $\begin{array}{c}\text { 2019/ Ribeirão preto (SP)/ Rev. Latino-Am. } \\
\text { Enfermagem }\end{array}$ & $\begin{array}{l}\text { Tranversal } \\
\text { quantitativo }\end{array}$ & $\begin{array}{l}\text { Síndrome de Burnout em trabalhadores de enfermagem } \\
\text { brasileiros e espanhóis }\end{array}$ \\
\hline COSTA SMS, et al. & 2020/Recife (PE) / Rev enferm UFPE online & Tranversal qualitativo & Síndrome de Burnout em profissionais de enfermagem \\
\hline FERREIRA GB, et al. & 2017/ Sobral (CE)/ Rev. Sanare, Sobral. & Observacional & $\begin{array}{l}\text { Síndrome de Burnout na enfermagem } \\
\text { Hospitalar/intensivista: o que dizem os Estudos? }\end{array}$ \\
\hline COSTA MEM, et al. & $\begin{array}{c}\text { 2017/ São Paulo (SP)/ Revista da Escola de } \\
\text { Enfermagem da USP }\end{array}$ & Observacional & $\begin{array}{l}\text { A síndrome do esgotamento profissional no contexto da } \\
\text { enfermagem }\end{array}$ \\
\hline $\begin{array}{l}\text { MACIEL APN e } \\
\text { GONÇALVES MJR }\end{array}$ & $\begin{array}{c}\text { 2020/ São Paulo (SP)/ Revista JRG de Estudos } \\
\text { Acadêmicos }\end{array}$ & Tranversal analítico & Incidência da síndrome de Burnout na enfermagem. \\
\hline SILVA RP, et al. & $\begin{array}{c}\text { 2015/ Rio de Janeiro (RJ)/ Arquivos Brasileiros de } \\
\text { Psicologia }\end{array}$ & Tranversal qualitativo & $\begin{array}{l}\text { Burnout e estratégias de enfrentamento em } \\
\text { profissionais de enfermagem }\end{array}$ \\
\hline OLIVEIRA RF, et al. & $\begin{array}{l}\text { 2017/ Belo Horizonte (MG)/ Revista de } \\
\text { Enfermagem do Centro-Oeste Mineiro. }\end{array}$ & Tranversal qualitativo & $\begin{array}{l}\text { Incidência da Síndrome de Burnout nos Profissionais de } \\
\text { Enfermagem }\end{array}$ \\
\hline FERNANDES LS, et al. & 2017/ Botucatu (SP)/ J. res.: fundam. Care. Online & Observacional & $\begin{array}{l}\text { Síndrome de Burnout em profissionais de enfermagem } \\
\text { de uma unidade de terapia intensiva }\end{array}$ \\
\hline PORTELA NLC, et al. & $\begin{array}{l}\text { 2015/ Rio de Janeiro (RJ)/ Revista de Pesquisa } \\
\text { Cuidado é Fundamental Online. }\end{array}$ & Tranversal qualitativo & $\begin{array}{l}\text { Síndrome de Burnout em profissionais de enfermagem } \\
\text { de serviços de urgência e } \\
\text { emergência }\end{array}$ \\
\hline SILVA JF, et al. & $\begin{array}{l}\text { 2020/ Brasília (DF)/ Revista Brasileira } \\
\text { Interdisciplinar de Saúde }\end{array}$ & Tranversal analítico & $\begin{array}{l}\text { A Síndrome de Burnout em profissionais de } \\
\text { enfermagem }\end{array}$ \\
\hline LOPES DF, et al. & $\begin{array}{l}\text { 2020/Val Paraíso de Goiás (GO)/ Revista de } \\
\text { Iniciação Científica e Extensão }\end{array}$ & Tranversal quantitativo & $\begin{array}{l}\text { Síndrome de Burnout e os seus efeitos sobre a vida dos } \\
\text { profissionais de enfermagem da urgência e emergência }\end{array}$ \\
\hline
\end{tabular}




\begin{tabular}{|c|c|c|c|}
\hline Autores & Ano, cidade e periódico de publicação & Tipo de estudo & Vertente do artigo \\
\hline MORENO JK, et al. & 2018/ Recife (PE)/ Rev enferm UFPE online & Tranversal quantitativo & $\begin{array}{l}\text { Síndrome de Burnout e fatores de estresse em } \\
\text { enfermeiros nefrologistas }\end{array}$ \\
\hline BATISTA KO, et al. & $\begin{array}{l}\text { 2019/Brasília (DF)/ Revista Brasileira } \\
\text { Interdisciplinar de Saúde }\end{array}$ & Tranversal qualitativo & $\begin{array}{l}\text { Síndrome de Burnout em enfermeiros: consequências } \\
\text { na atividade profissional }\end{array}$ \\
\hline SILVA GSA, et al. & 2018/São Paulo (SP)/. Cient. Sena Aires. & Tranversal quantitativo & $\begin{array}{l}\text { Estresse e Burnout em profissionais de enfermagem de } \\
\text { unidade de terapia intensiva e semi-intensiva }\end{array}$ \\
\hline MOTA ID, et al. & 2017/ Florianopolis (SC)/ Rev. Motrivivência & $\begin{array}{l}\text { Transversal } \\
\text { analítico }\end{array}$ & $\begin{array}{l}\text { Síndrome de Burnout em estudantes universitários: um } \\
\text { olhar sobre as investigações }\end{array}$ \\
\hline BRITO TB, et al. & 2019/ Maringá (PR)/ Revista Uningá & Observacional & $\begin{array}{l}\text { Síndrome de Burnout: Estratégias de prevenção e } \\
\text { tratamento nos profissionais de enfermagem. }\end{array}$ \\
\hline SILVA KSG, et al. & $\begin{array}{c}\text { 2020/São João Del Rei (MG)/ Revista Eletrônica } \\
\text { Acervo Saúde }\end{array}$ & Observacional & $\begin{array}{l}\text { Síndrome de Burnout em profissionais de Enfermagem } \\
\text { no contexto da Atenção Básica }\end{array}$ \\
\hline BASTOS JC, et al. & $\begin{array}{l}\text { 2017/ Manaus (AM)/ Revista Eletrônica Acervo } \\
\text { Saúde }\end{array}$ & Tranversal quantitativo & $\begin{array}{l}\text { Síndrome de Burnout e os estressores relacionados à } \\
\text { exaustão emocional em enfermeiros }\end{array}$ \\
\hline SANTOS EN, et al. & 2019/São Paulo (SP)/ Rev Nursing & Experimental & $\begin{array}{l}\text { Saúde do trabalhador no ambiente hospitalar: fatores } \\
\text { de risco para síndrome de Burnout }\end{array}$ \\
\hline $\begin{array}{l}\text { BRAGA DS e PAULA } \\
\text { MAB }\end{array}$ & $\begin{array}{l}\text { 2018/Taubaté (SP)/ Rev Prog de Pós-Graduação } \\
\text { em Humanidades, Culturas e Artes (UNIGRANRIO) }\end{array}$ & Observacional & Síndrome de Burnout em profissionais de enfermagem \\
\hline $\begin{array}{l}\text { PERNICIOTTI PSJ, et } \\
\text { al. }\end{array}$ & 2020/ São Paulo (SP)/ Rev. SBPH & Tranversal qualitativo & $\begin{array}{l}\text { Síndrome de Burnout nos profissionais de saúde: } \\
\text { atualização sobre definições, fatores de risco e } \\
\text { estratégias de prevenção }\end{array}$ \\
\hline
\end{tabular}

Fonte: Vilaço RLB, et al., 2021. 


\section{DISCUSSÃO}

Diante dos estudos selecionados, pode-se constatar que há uma vasta literatura relacionada ao Burnout. Tal síndrome está associada a disfunções pessoais no relacionamento entre o homem e seu trabalho (MOTA ID, et al. 2019). Logo, buscou-se entender nesse estudo, os mecanismos fisiológicos que levam uma gama de profissionais da enfermagem a serem acometidos pelo Burnout, sendo de grande relevância para toda a sociedade o debate sobre esta temática, com o interesse de fomentar melhorias para a saúde de maneira geral.

Os estudos de Bastos JC (2021), Oliveira RF, et al. (2017), Braga DS e Paula MAB (2018), Maciel APN e Gonçalves MJR (2020), apontam a sobrecarga de trabalho dentro das unidades hospitalares ocasionada pela alta demanda e ao déficit de pessoal como um fator importante. Confirma esse entendimento o estudo de Lopes DF, et al. (2020), o qual aponta ser este um fator real no cotidiano dos profissionais da enfermagem que atuam na urgência e emergência.

Outro fator relevante para a alta incidência da síndrome de Burnout nos profissionais da enfermagem é a alta demanda, tanto na Atenção Primária de Saúde, como em outros setores: Pronto Atendimentos e Unidade de terapia Intensiva, o que implica em maiores exigências e excesso de trabalho e dedicação, diante da necessidade de atuar com velocidade e exatidão na realização das tarefas e da grande responsabilidade em todas as atividades desenvolvidas e exposição às situações de risco de morte e sofrimento intenso dos pacientes, levando-os a vivenciar uma rotina complexa (SILVA JF, et al., 2020; PERNICIOTTI PSJ, et al., 2020; FERREIRA GB, et al., 2017).

Neste sentido, destaca Perniciotti PSJ, et al. (2020), que a equipe de enfermagem enfrenta sentimento de frustração e ameaças contínuas (devido as demandas excessivas e falta de recursos para atendê-las) à sua saúde física e/ou mental em seu ambiente de trabalho.

Outros estudos de Brito TB, et al. (2019), Braga DS e Paula MAB (2018), explicam que a equipe de enfermagem trabalha de forma prolongada, com carga horária semanal superior a 40 horas semanais, bem como, em finais de semana, no horário noturno. Concordam também outros estudiosos do tema, afirmando que esse carga exaustiva leva os profissionais a desenvolverem fadiga, angústia, estresse, ansiedade, desânimo, hostilidade e agressividade (FERNANDES LS, et al., 2017; LOPES DF, et al., 2020). Concordam que a equipe de enfermagem sofre muito com extensão de tempo aumentada e com recursos quase que totalmente limitados para o desenvolvimento do trabalho (SILVA JF, et al., 2020, COSTA MEM, et al., 2017).

Soma-se a todos esses aspectos, o fato de que apesar de atender uma demanda alta, trabalhar em período prolongados com excesso de carga laboral, o profissional de enfermagem ainda é mal remunerado, o que lhe obriga a aceitar realizar duplas jornadas o que vem somar aos fatores desencadeadores do estresse. Face ao exposto, compreende-se que os profissionais da enfermagem findam se submetendo, em algum momento, a uma condição de desgaste crônico, que os deixa suscetíveis ao esgotamento laboral (OLIVEIRA RF, et al., 2017; MOTA ID, et al., 2019).

Portanto, é preciso melhorar o retorno financeiros dos profissionais de enfermagem para evitar que busquem realizar essa dupla jornada, destacando que o investimento tem retorno garantido em aumento da produtividade e qualidade no atendimento e satisfação do paciente, como é afirmado na literatura (MORENO JK, et al., 2018; SILVA KSG, et al., 2020; SILVA GSA, et al., 2018).

Citam-se também como fatores estressores a falta de proteção adequada (EPIs), haja vista que, as condições inadequadas de trabalho são precárias, estando sempre sujeitos a serem contaminados, e, além de sofrerem com os fatores já elencados, estes profissionais sofrem com o sentimento da insegurança, em ambientes de risco, insalubres sem a devida proteção, até mesmo dos mais básicos como máscaras e luvas, bem como precisam fazer uso de Equipamentos de Proteção Individual sem Certificado de Aprovação, de procedência duvidosa (BRAGA DS e PAULA MAB 2018; SILVA JF, et al., 2020; PORTELA NLC, et al., 2015).

Já Lopes DF, et al. (2020) e Baldonedo MM, et al. (2019), indicam em seus estudos, outro fator: a ambiguidade de papéis em relação a equipe de enfermagem, como fator gerador de grandes esforços físicos 
e mentais, relacionados ao estresse e ao Burnout. Sendo que é comum, no ambiente laboral os profissionais da enfermagem precisarem atuar em diversas funções e conviver com situações conflituosas, o que desencadeia o cansaço e o estresse, podendo trazer danos ao profissional mentalmente e interferindo, também, em um melhor relacionamento entre paciente e enfermeiro e relação entre a própria equipe de enfermagem e profissional da enfermagem e instituição (MORENO JK, et al., 2018).

Silva KSG, et al. (2020) também reforça que, as cobranças dos setores em que o enfermeiro atua, como sendo demasiadas, os desentendimentos no ambiente de trabalho, a intolerância de erros, dentre outros fatores, que fazem com que o profissional de enfermagem entre um quadro de aflição, angústia, insatisfação, desânimo, estresse total e, consequentemente, adoecimento, adquirindo inclusive, a síndrome de Burnout.

Outro fator elencado é a desmotivação, destacado como ápice para desencadear a síndrome o esgotamento ou exaustão emocional e física, decorrentes das exigências do trabalho; e conforme for se agravando, pode desencadear um processo de despersonalização e até cinismo, levando estes profissionais tão importantes para o cuidado a se tornar indiferente a dor do outro, colegas e pacientes, acarretando prejuízo qualidade do serviço oferecido e ineficácia no atendimento (OLIVEIRA RF, et al., 2017; BATISTA KO, et al., 2019; FERNANDES LS, et al., 2017; MORENO JK, et al., 2018; PERNICIOTTI PSJ, et al., 2020; SILVA GSA, et al., 2018).

Santos EN, et al. (2019) e Costa SMS, et al. (2020), explicam que nesse momento crítico de exaustão os indivíduos sentem queda na imunidade e desenvolvem doenças. Sendo que a exaustão emocional acontece quando o profissional vem tendo sentimentos recorrentes de fadiga, falta de energia para enfrentar as situações desafiadoras e exigentes da sua rotina de trabalho. A despersonalização ocorre quando o profissional se mostra insensível com os colegas e usuários no ambiente laboral, se distanciando das pessoas e se endurecendo no que tange a expressão de afeto. E a reduzida Realização Profissional, as qual afeta o trabalhador a ponto ele sentir-se muito insatisfeito em relação a execução de suas atividades laborais, levando-o a se desapegar ao trabalho e desencadeando sentimento de frustração (SANTOS EN, et al., 2019).

Bastos JC (2021), sugere que sejam desenvolvidos programas e condutas que possam levar a equipe de enfermagem a uma boa promoção de saúde mental, a fim de evitar que tais profissionais desenvolvam o Burnout. Pois, ao se investir em treinamentos, aumento do quadro de funcionários, suporte psicológico, aumento de salário e na melhoria de qualidade de vida desses profissionais, tanto eles como os pacientes e as instituições hospitalares podem ser beneficiadas, haja vista que os mesmo atuariam motivados e satisfeitos, estendendo estes benefícios aos pacientes por meio de atendimento humanizado e qualificado, bem como à instituição financeira por meio de aumento da produtividade e satisfação do paciente.

Lopes DF, et al. (2020), Batista KO, et al. (2019) e Silva RP, et al. (2015), recomendam o aumento de membros das equipes de enfermagem, a fim de atender a demanda de forma justa. Santos EN, et al. (2018), concordam que é necessário um diálogo permanente entre planejamento, execução e gestão a fim de minimizar os fatores que levam ao estresse e ao Burnout.

\section{CONSIDERAÇÕES FINAIS}

Foram evidenciados nesse estudo que há similaridades no que tange os fatores desencadeadores do Burnout com outros estudos. São eles: sobrecarga laboral, baixa remuneração, intolerância aos erros ambiente de trabalho conflituoso, ambiguidade de funções, sendo o profissional de enfermagem, em muitos casos, precisa realizar atividades e funções que não são suas, tudo isso somado às condições inadequadas de trabalho, como a ausência de Equipamentos de Proteção Individual e falta de insumos e estrutura para melhor atender levam ao desgaste físico e psíquico. O tema não se esgota, este estudo apenas contribui como subsídio para futuras intervenções, com o interesse melhorar as condições de trabalho dos referidos profissionais da saúde.

\section{REFERÊNCIAS}

1. BALDONEDO MM, et al. Síndrome de Burnout em trabalhadores de enfermagem brasileiros e espanhóis. Revista Latino-Americana de Enfermagem, 2019; 7: e3192. 
2. BASTOS JC, et al. Síndrome de Burnout e os estressores relacionados à exaustão emocional em enfermeiros. Revista Eletrônica Acervo Saúde, 2021;13(2): 1-10.

3. BATISTA KO, et al. Síndrome de Burnout em enfermeiros: consequências na Atividade profissional. Revista Brasileira Interdisciplinar de Saúde (ReBIS), 2019; 1(24): 61-5.

4. BRAGA DS, PAULA MAB. Síndrome de Burnout em profissionais de enfermagem. Revista do Programa de PósGraduação em Humanidades, Culturas e Artes (UNIGRANRIO), 2018; 1(17): 29-43.

5. BRANCO FMFC, et al. Síndrome de Burnout entre trabalhadores de uma universidade na fronteira franco brasileira. Rev Fun Care Online, 2020; 12: 393-399.

6. BRASIL. Ministério da Saúde. Síndrome de Burnout: o que é, quais as causas, sintomas e como tratar. 2019. Disponível em: http://www.saude.gov.br/saude-de-a-z/saude-mental/sindrome-de-burnout. Acessado em: 26 de junho de 2020.

7. BRASIL. Confederação Nacional dos Trabalhadores da Saúde. 87\% dos enfermeiros apresentam sintomas de esgotamento, aponta estudo. 2020. Disponível em: https://www.condsef.org.br/noticias/87-dos-enfermeirosapresentam-sintomas-esgotamento-aponta-estudo. Acessado em: 26 de junho de 2020.

8. BRITO TB, et al. Síndrome de Burnout: estratégias de prevenção e tratamento nos profissionais de enfermagem. Revista Uningá, 2019; 56(2): 113-122.

9. CONSELHO FEDERAL DE ENFERMAGEM (COFEN). Enfermagem em números. Rio de Janeiro, 2020. Disponível em: http://www.cofen.gov.br/enfermagem-em-numeros. Acesso em: 14 de Outubro de 2020.

10. COSTA MEM, et al. A síndrome do esgotamento profissional no contexto da enfermagem: uma revisão integrativa da literatura. Revista da Escola de Enfermagem da USP, 2017; 51: e03235.

11. COSTA SMS, et al. Síndrome de Burnout em profissionais de enfermagem. Rev enferm UFPE on line, $2020 ; 14$ (1):e243351

12. FERREIRA GB, et al. Síndrome de Burnout na enfermagem Hospitalar/intensivista: o que dizem os Estudos? Sanare, Sobral, 2017; 16(1): 100-108.

13. FERNANDES LS, et al. Burnout Syndrome in nursing professionals from an Intensive Care Unit. Rev Fund Care Online, 2017; 9(2): 59-67

14. FRANCA FM, FERRARI R. Síndrome de Burnout e os aspectos sóciodemográficos em profissionais de enfermagem. Acta paul. Enferm, 2012; 25(5): 743-748.

15. INTERNATIONAL STRESS MANAGEMENT ASSOCIATION (ISMA). Brasil é o 2ำ país com o maior número de

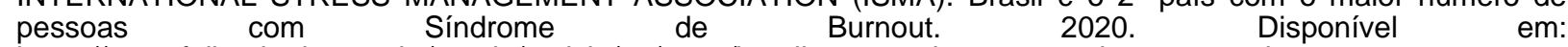
https://www.folhavitoria.com.br/saude/noticia/08/2020/brasil-e-o-2-pais-com-o-maior-numero-de-pessoas-comsindrome-de burnout\#: :text=De\%20acordo\%20com\%20a\%20International,n\%C3\%ADvel\%20de\%20estresse\%2C\%20no\%20m undo. Acessado em: 26 de junho de 2020.

16. LOPES DF, et al. Síndrome de Burnout e os seus Efeitos sobre a Vida dos Profissionais de Enfermagem da Urgência e Emergência. Rev Inic Cient Ext., 2020;3(1): 350-355.

17. MACIEL APN, GONÇALVES MJR. Incidência da síndrome de Burnout na enfermagem. Revista JRG de Estudos Acadêmicos, 2020; 3(6): 96-109.

18. MORENO JK, et al. Síndrome de Burnout e fatores de estresse em enfermeiros nefrologistas. Rev. enferm. UFPE on line, 2018; 12(4): 865-871.

19. MOTA ID, et al. Síndrome de Burnout em estudantes universitários: um olhar sobre as investigações. Motrivivência, 2017; 29: 243-256.

20. OLIVEIRA RF, et al. Incidência da Síndrome de Burnout nos Profissionais de Enfermagem: Uma Revisão Integrativa. Revista de Enfermagem do Centro-Oeste Mineiro, 2017; 7(1): e. 1383.

21. ORGANIZAÇÃO PAN-AMERICANA DE SAÚDE (OPAS). CID: Burnout é um fenômeno ocupacional. 2019. Disponível em: https://www.paho.org/bra/index.php?option=com_content\&view=article\&id=5949:cid-burnout-e-um-fenomenoocupacional\&Itemid=875. Acesso em: 22 de junho de 2020.

22. PERNICIOTTI PSJ, et al., Síndrome de Burnout nos profissionais de saúde: atualização sobre definições, fatores de risco e estratégias de prevenção. Revista da SBPH, 2020; 23(1): 35-52.

23. PINTO M, et al. Síndrome de Burnout em docentes. Revista Interdisciplinar, 2015; 8(2): 169-177.

24. PORTELA NLC, et al. Síndrome de Burnout em profissionais de enfermagem de serviços de urgência e emergência. Rev. Pesqui., 2015; 7(3): 2749-2760.

25. SANTOS EM, et al. Saúde do trabalhador no ambiente hospitalar: fatores de risco para síndrome de Burnout Nursing, 2019; 22(2): 440-448.

26. SILVA GSA, et al. Estresse e Burnout em profissionais de enfermagem de unidade de terapia intensiva e semiintensiva. Rev. Cient. Sena Aires, 2018; 7(1): 5-11.

27. SILVA JF, et al. Síndrome de Burnout em profissionais de Enfermagem no contexto da Atenção Básica. Revista Eletrônica Acervo Saúde, 2020; 39: e2320.

28. SILVA KSG, et al. A síndrome de Burnout em profissionais de enfermagem. Revista Brasileira Interdisciplinar de Saúde (ReBIS), 2020; 2(1): e24441.

29. SILVA RP, et al. Burnout e estratégias de enfrentamento em profissionais de enfermagem. Arquivos Brasileiros de Psicologia, 2015; 67(1): 130-145. 